\title{
APPLICATION OF DIDACTIC GAMES IN MATHEMATICS TEACHING
}

\author{
Predrag Vuković ${ }^{1 \star}$, Anamarija Juras ${ }^{2}$ \\ ${ }^{1}$ Prof. Dr., University of Zagreb, Faculty of Teacher Education, CROATIA, \\ predrag.vukovic@ufzg.unizg.hr \\ ${ }^{2}$ University of Zagreb, Faculty of Teacher Education, CROATIA, ajuras20@gmail.com \\ ${ }^{*}$ Corresponding Author
}

\begin{abstract}
The purpose of this paper is to show the importance of the use of games and didactic games, especially in the initial teaching of mathematics. We explain the connection between the didactics and the curriculum as well as the types of didactic games and the ways in which they can be used in mathematics teaching. The research part of the paper is based on the results of the questionnaire on the application of didactic games in mathematics teaching. The research, which was conducted among 274 primary school teachers, sought to determine whether didactic games are used in mathematics teaching and which games they use most often. Also, attitudes about the advantages and disadvantages of the didactic game in teaching and how the game affects the student in the educational process were examined. Teachers also had the opportunity to comment on how they can change the use of didactic games and materials. The research problem states that primary school teachers use didactic games in their teaching and try to keep up with the times. Furthermore, research has proven that play is very important to students because it motivates them for teaching content, and they also become more active participants in the educational process.
\end{abstract}

Keywords: game, didactic games, teaching mathematics, student activity

\section{INTRODUCTION}

In the hectic world we are in, the world where technology is advancing day by day, it is evident that today's teaching and fast-paced lifestyle require change. Students in this new and modern world get bored of an activity really quickly and change is required, and in this way teaching can be made more dynamic and interesting. The recipe for success, especially in the lower grades, lies in the game. The game is a social phenomenon, it arouses interest, with the game we relax, rest, enjoy. According to Bognar (1986, p. 7), there are three theories of play - sociological, psychological and pedagogical theory, but none of them offers an adequate explanation of what play really is. The easiest way to explain play is as an immanent activity through which children, but also adults, discover their possibilities and abilities, acquire skills, habits and experiences, learn and compete in something where it is expressed how good someone is in something. Also, the game is closely related to teaching, and the use of innovative games and materials in teaching allows active participation of students in the process of education.

Initial teaching of mathematics has a very important role in the life of every student because mathematical abstractions and laws in the classroom are a prerequisite for subject teaching, but also other knowledge in this area. Concretization is extremely important in mathematics, and one of the ways to achieve it is by using didactic materials in teaching. Of course, it would be even better if some didactic toys are used in the earliest 
childhood, because a child learns from an early age at any time, and thus creates awareness of what he has learned. Play is their most fun form of learning and every parent should know that when they think it doesn't matter how a child plays and what they play with, they absorb it like a sponge, learn, and the knowledge they gain through play becomes more lasting than any other way. Didactic materials and games help to make teaching dynamic and fun, but also maintain students' concentration and activity for longer, which greatly contributes to making teaching even better.

The aim of this research was to examine the opinions of primary school teachers on whether they use any didactic games in mathematics teaching, in which domains and whether they use some other types of didactic materials. This research aims to show which games and materials are most often used in the initial teaching of mathematics and how the use of didactic games and materials affects students and how we can improve them.

\section{GAME, MATHEMATICS AND TEACHING}

The relationship between play and work from the earliest past is interesting to many scholars as play opens up a new relationship to work. In the work of the Dutch cultural theorist and historian, Johan Huizinga (1970) Homo ludens: on the origin of culture in play, it is evident that play is the primary and necessary condition of the generation of culture. Huizinga is also known for his belief that "human culture grew and developed from play - and as play." Huizinga thus developed a characteristic theory of play that play is a very important characteristic of man and society, but that play is not real life. It differs in duration and place, and is filled with rhythm and harmony. The game is also characterized by some rules that then determine the norms. $\mathrm{He}$ also states that play is a struggle for something, or a competition in which one expresses how much one can do something best (Huizinga, 1970).

It is assumed that play is a natural means in which a child can express his thoughts and feelings, through play he can express his problems, but also emotions. At the core of the game are not specific instincts, but general instincts, and Buytendijk in his work Essence and Play's Sense (1933) lists three instincts that lead to the game: the instinct for liberation (autonomy), the instinct for unification with the environment and the instinct for repetition. Therefore, play arises when these instincts are found to conflict with objects, but we must be careful when choosing objects because not every object is suitable for play. The most suitable items for the game are those that are familiar to children and contain a number of undiscovered possibilities that the subject can do. On the other hand, items that are completely unknown are inappropriate.

Representatives of the so-called new school emphasize the need for the child's activities in the process of upbringing and education. One of them was the philosopher and educator John Dewey who emphasizes the importance of play and work in education (Bognar, 1986). Dewey thinks that there should be no distinction between play and work because both play and work presuppose conscious acceptance of the goal and selection and adaptation of materials to achieve the goal we want (Bognar, 1986). Interest in the use of various games and materials in teaching has emerged in the last fifty years as a result of various studies. Many of these researches were based on the gradual transition from pre-school to school education by using play. Through play in primary school, students are still offered content that they "must" learn, but again in such a way that the transition was adapted to the child. Games represent a bridge that carries research and work period, and this is exactly what is visible in the way of working in the first grade where we provide students with the most elements of the game, stories are told, conversations are relaxed, and the emphasis is on reading and writing together. Franković (2016) says that the application of play in teaching can increase the interest in learning.

Liebeck (1995) argues that mathematics is an abstraction of reality and that all children's experiences, including mathematical ones, develop in a certain sequence, following the E-L-P-S model. The letter E represents the experience of physical objects, the letter $L$ is the spoken language that describes that experience, the letter $\mathrm{P}$ are pictures depicting the experience, and the letter $\mathrm{S}$ are written signs that generalize that experience (Liebeck, 1995). Students in the lower grades of primary school are in the phase of concrete operations of cognitive development in which they come to conceptualization through their own experiences. In the following example, we will show with the help of the E-L-P-S model the teaching unit "Multiplication of number 3 " on the set model.

Letter $\mathrm{E}$ (experience) - Students have a manipulative object, beads. They were told to put together four sets so that there were three beads in each set. Students use beads and put together four piles (sets) and put three beads (elements) in each set. The main activity here is counting the elements of the set (Glasnović Gracin, 2012).

Furthermore, the question arises as to how the teaching of mathematics and the game itself are related. We 
can freely say that the teaching of mathematics is in many ways specific in relation to the remaining subjects, and thus it is often difficult to achieve the tasks and goals in this subject. According to Levar and Lukačić (2014), mathematical games are methods by which we can motivate children and more actively involve them in the educational process because in a close way we facilitate the mastery of teaching content. The goal of teaching mathematics is not just to strictly follow the curriculum, it is important that by choosing tasks related to the curriculum to alleviate the rigidity of the program and point to another face of mathematics - its bright side that includes creativity, imagination, curiosity and play. Logical and creative thinking is extremely important for students in mathematics. According to Krowatscek D. and Krowatscek G. (2007, p. 22), unlike lateral thinking where not every step is required, in logical thinking every step is very important and must be accurate. Logical reasoning therefore makes judgments immediately, while in lateral judgment can be postponed. By learning the subject of mathematics, students encounter various problems that encourage them to think, explain, prove, but also draw conclusions, and the process of thinking is of great importance.

\section{METHODOLOGICAL FRAMEWORK}

The methodology of education research has a number of different research tools, approaches and methods of data collection and analysis, but in this research a quantitative approach was predominantly used with regard to the epistemology and ontology of the research (Cohen, Manion and Morrison, 2007; Creswell, 2012; Dubovicki and Topolovčan, 2020; Matijević and Topolovčan, 2017). Since the questionnaire also asked open-ended questions, we can talk about the approach of mixed methodology, because in addition to quantitative, it also contains qualitative data.

The research section of the paper is based on the results of a survey on the application of didactic games in mathematics teaching. The procedure used for data collection contained a questionnaire that was posted in groups on social networks (Facebook) and an online questionnaire sent to the e-mail addresses of primary school teachers in the Republic of Croatia, who then forwarded it to their colleagues within the team. The questionnaire was intended for all primary school teachers, and the purpose and goal of the survey were used exclusively for the purposes of writing of this paper. Participation in the survey was anonymous and voluntary, and respondents were asked to answer questions honestly. The questionnaire was accessed by 274 respondents, and the questionnaire contained a total of 18 questions. The first five questions were questions related to general data on respondents - gender, university degree, work experience, whether they are computer science teachers and whether they work in a rural or urban school. The remaining thirteen questions focused on the use of didactic games in teaching.

More women $(76.3 \%)$ than men $(23.7 \%)$ joined the survey, and the results are not surprising, but it was thought that the survey would still be attended by fewer men than expected, due to the fact that there are always more women in education. Furthermore, it is interesting that the figures in the years of work experience do not differ much, so the survey was attended by both young and older, more experienced population, and most respondents do not teach computer science.

\section{RESEARCH RESULTS}

The data obtained from the survey questionnaire in online form (Google forms) were processed with the help of Microsoft Excel 2010, and with the help of IBM SPSS Statistics 2020. The data from the survey questionnaire are presented below.

The first few questions were related to general data on the respondents, and the remaining questions were related to didactic material and games and their use in mathematics teaching. The first question in this series was if teachers had ever used any didactic material. Thus, 269 respondents answered in the affirmative, and 5 of them answered in the negative to this question.

The second question was related to the previous one, and that was to indicate which of the offered games / materials they used in teaching. The following answers were offered in the survey: digital games, drama games, memory, associations, Montessori material, number line, tangram puzzles, sticks or beads, magnetic puzzles and arithmetic caterpillar. The largest percentage of respondents, as many as 213 , said that they use the number line the most, followed by memory and digital games. At the top there is also a game of association, sticks or beads and a calculating caterpillar. The smallest percentage of respondents use Montessori material in teaching.

This was followed by the question in which subjects they use games and materials. The offered answers were: Croatian language, mathematics, nature and society and others. Thus, 265 respondents stated that they use games and materials in mathematics, and it is evident that the percentages are high in other subjects as well. This question had the possibility of multiple choice answers. 
The next issue was related to the possession of materials in their schools. Out of 274 respondents, 30 answered that they do not have games and materials in the school, which is a little unthinkable and difficult for the school in the 21st century to imagine, but there are still schools that are better equipped and invest more. When asked whether they use didactic games in the subject of mathematics, only 6 respondents gave a negative answer.

After that, they were asked to indicate which games they use in mathematics, and they had the following to choose from: memory, associations, rebus, crossword puzzles, bingo, dice games, card games, math chain, puzzle, dominoes and more. Dice games, card games, memory and bingo according to the obtained results are the most common games in teaching mathematics. Also, a lot of respondents use the remaining games offered, and as many as 46 stated that they use some other games besides those listed here.

When they marked the games, the respondents were offered the following question, and that is in which domain they use the most didactic games. The survey offered domains: numbers, algebra and functions, shape and space, measurement and data, statistics and probability. Also, they could choose more answers in this question, and the results show that games are most used in the numbers domain, followed by the shape and space measurement domain. It should be mentioned that 4 respondents answered that they do not use games in any domain.

Also, the following question was aked: in which part of the math class the respondents most often use didactic games? The answers offered were: introductory part, main part, final part and I do not use, and most respondents answered that they use games in the final part. Also, as in the previous question, 5 respondents stated that they do not use games in any part of the class.

The question that followed was whether they think that didactic games influence a student to become a more active participant in the educational process, so $95.3 \%$ of respondents (261 respondents) answered in the affirmative, and $4.7 \%$ (13 respondents) answered in the negative.

The most common answers that occur to teachers are those that say that it is interesting for students to learn through play, games arouse interest and compete.

After the questions related to the use of games and materials, the teachers had to indicate on the next two questions what they think are the advantages and what are the disadvantages of using didactic games. Among the advantages, they had the following statements: Students are more motivated and ready to work; Attention and concentration are at a higher level longer; Games encourage communication, cooperation and student activity; Games develop imagination and creativity; It is easier for students to adopt the teaching content with the game; The game gives quick feedback on adoption; Involvement of all students regardless of opportunities and abilities. Also, the respondents had the possibility of multiple choice in this issue. $83.6 \%$ of respondents (229 respondents) were in favor of the statement "Students are more motivated and ready to work", followed by the statement "Students learn teaching content more easily through play", which was chosen by $76.3 \%$ of respondents (209 respondents) ). $63.9 \%$ of respondents (175 respondents) agree with the fact that the game gives quick feedback on adoption, followed immediately by $62 \%$ of respondents ( 170 respondents) the following statement: Games encourage communication, cooperation and activity of students. For the statement "Involvement of all students regardless of opportunities and abilities" $54 \%$ of respondents (148 respondents) decided, while $52.6 \%$ of respondents (144 respondents) decided for the statement "Games develop imagination and creativity". The last statement is "Attention and concentration are longer at a higher level", which was chosen by $51.8 \%$ of respondents, or 142 respondents.

In the case of shortcomings, the following claims were offered: Lack of time for implementation; Longer and more complex preparation in classes where the game is used; Lack of materials, equipment or technology; Noise in the classroom; A special approach for students with regard to difficulties. Most respondents chose the statement "Lack of materials, equipment or technology" as the biggest shortcoming, as many as $75.5 \%$ of respondents (207 respondents). This is followed by the statement "Longer and more complex preparation in classes where the game is used" which was chosen by $66.8 \%$ of respondents (183 respondents) and the statement "Lack of time for implementation" which was chosen by $56.2 \%$ of respondents (154 respondents). $36.9 \%$ of respondents (101 respondents) decided to make noise in the classroom, and $21.2 \%$ of respondents (58 respondents) affirmed the statement "Special approach for students due to difficulties".

The last question in the questionnaire was open-ended, and teachers were asked their opinion on how they could improve the use of didactic games and materials in teaching mathematics.

We can conclude that the equipment of the school is a prerequisite for improving the use of didactic games. Also, it is evident from the answer that a larger selection of possible games and the necessary material 
should be offered, and professional gatherings should be provided where teachers (especially older and more experienced) would see examples of games. Preparing such classes requires 3-4 times more time from the teacher, which is why there should be a list and methodical implementation of games. Furthermore, great stress is created by the subject curriculum and the program that must be followed. Many answers say that it is all too extensive and when you do what you have to do, there is not much time left to play and teach in that way.

\section{DISCUSSION AND CONCLUSION}

As can be seen in the obtained results, a total of 274 respondents participated in the survey questionnaire, of which 209 were female and 65 were male. Respondents in the research believe that didactic games influences a student to become a more active participant in the educational process. By using didactic game, the student has the opportunity to improve their skills or adopt new ones, while practicing the teaching content. If used in such a way that it is individual work, the student is completely immersed in the task. Most of the time, they are not aware of how much they have learned by playing, that is, through fun. This research examined the attitudes of primary school teachers about the use of didactic material and games in mathematics teaching, and according to the results it is clear that this material makes it easier for them to teach mathematical content given the difficulties encountered in processing. Also, it was assumed that teachers in the lower grades use different games and materials in order to move away from traditional teaching and frontal teaching itself, which was shown by this research. As the main advantages of games, teachers stated that students are more motivated to work, with the game they learn more easily, the game gives quick feedback on adoption and the game encourages creativity, imagination and different ways of solving problems. We can connect these results with the opinions of Franković (2016) who states that the interest in learning increases if the game is used in teaching. Games provide an interesting environment in which students acquire knowledge and are away from everyday life, so students are more motivated to work. As disadvantages, they mentioned the lack of materials, equipment and technology, as well as the longer and more complex preparation required for some of these forms of teaching. Their suggestions for improving the use of didactic games concern ready-made materials and games. Teachers still work a lot outside of working hours and need to invest much more effort and time to prepare materials and games, which they often do not have, so it would be good for them to add even more ready-made templates with textbook sets. Also, a lot of the answers were related to education about games and their use. Many believe that if the game does not have a goal and purpose, its implementation is purposeless and that there is still a need for improvement in this field. This is in concordance with the statements made by Mlinarević (2002) that it is crucial to provide teachers with education and seminars to improve their work, but also to know how to use and use games and materials in the right way in teaching.

The last answer that came out the most frequently was the cooperation of teachers with each other. Many of them have only now, at the time of the pandemic, decided to ask for help from colleagues, and they also stated that they are now helping each other more, sending materials, ideas, tasks. It is clear how important mutual cooperation between teachers is and how much it affects their work. The results can also be compared with the statements made by Booker (2000) - games are important in the way of solving problems, improve students' skills and support social interactions, and they influence learning.

Game and didactic game have their own characteristics and rules, and in addition to fun, they are in the function of learning and teaching. Their use has a positive effect on the activity, motivation and attention of students, but each game should be used properly and adapted to the age and abilities of students. The goal should be to achieve the goal of upbringing and education, and concretization will greatly help students in the acquisition of abstract mathematical concepts.

From the research conducted, it is clear how teachers use didactic games and materials in the initial teaching of mathematics. They most often use dice and card games, memory, bingo, math crosswords, associations, puzzles. From the results we can conclude that these are mostly self-made materials (or materials that can be found on the Internet and are available for printing), so teachers dedicate a lot of time to their production. Also, according to the results obtained, teachers would like didactic materials to be available with textbook kits and that there are universal templates that can be used in several areas to save a little time. Many also believe that additional education on their use is needed.

Didactic games are mostly used in the final part of the lesson, and only then, in the second place, according to the respondents, is the introductory part. We find this desirable because students lose attention and concentration as we move towards the end of the class, especially 1st grade students who still find 45 minutes of sitting in peace difficult to accept, and through the game we still keep the activity until the end of the class. According to S. S. Boocock, from research conducted in the United States, we can conclude that 
play increases a student's motivation and interest, and makes learning more interesting than other ways of working. Also, games can be applied to students of lower abilities and capabilities so that such students do not feel isolated from the rest of the class (Boocock,1971, according to Bognar, 1986). Identical arguments were made by primary school teachers in the above research. The use of didactic games enables an educational and fun way of processing teaching content and achieving learning outcomes, and they should be an indispensable part of teaching mathematics.

Through the game students think logically, have a desire to learn and love a subject that they may not have so far. By playing, they also develop cooperative relationships and learn to respect other people's opinions, but also in this way satisfy basic human needs. Also, if they independently design and make games, they improve their knowledge and develop creativity. Because teachers are very important and play a big role in the lives of their students, they are models they will emulate. Therefore, in addition to teaching children the prescribed curriculum, they also teach them perseverance, understanding, cooperation and tolerance towards others.

\section{REFERENCE LIST}

Bognar, L. (1986). Igra u nastavi na početku školovanja. Zagreb: Školska knjiga

Booker, G. (2000). The Math Games: Using Instructional Games to Teach Mathematics. New Zealand Council for Educational Research.

Buytendijk, F.J.J. (1933). Wesen und Sinn des Spiels. Das Spielen des Menschen und der Tiere als Erscheinungsform der Lebenstriebe. Berlin: Kurt Wolff

Cohen, L., Manion, L., Morrison, K. (2007). Research Methods in Education. Sixth Edition. London i New York: Routledge.

Creswell, J. W. (2012). Educational research: planning, conducting and evaluating quantitative and qualitative research. Pearson.

Dubovicki, S., Topolovčan, T. (2020). Through the looking glass: methodological features of research of alternative schools. Zagreb: Letnik.

Glasnović Gracin, D. (2012). Upotreba konkretnih materijala u razrednoj nastavi matematike. Zbornik radova 5.Kongresa nastavnika matematike Republike Hrvatske, 197-202. Zagreb: Profil.

Huizinga, J. (1970). Homo ludens. Zagreb: Matica hrvatska

Krowatschek, D, Krowatschek, G. (2007). IQ trening - razmišljanje objema polovicama mozga. Zagreb: Alka script.

Levar, T, Lukačić, K. (2014). Matematika kroz igru - radionica. Poučak, 15(60): 26-40.

Liebeck, P. (1995). Kako djeca uče matematiku: metodički priručnik za učitelje razredne nastave, nastavnike i profesore matematike. Zagreb: Educa.

Matijević, M. i Topolovčan, T. (2017). Multimedijska didaktika. Zagreb: Školska knjiga i Učiteljski fakultet.

Mlinarević, V. (2002). Učitelj i odrednice uspješnog poučavanja. Život i škola. https://bib.irb.hr/datoteka/505871.505871.Ucitelii i odrednice uspjesnog poucavanja.pdf 